\title{
Urgences
}

\section{Extraits de Calendrier}

\section{Michel Savard}

Numéro 3, 4e trimestre 1981

URI : https://id.erudit.org/iderudit/025038ar

DOI : https://doi.org/10.7202/025038ar

Aller au sommaire du numéro

Éditeur(s)

Urgences

ISSN

0226-9554 (imprimé)

1927-3924 (numérique)

Découvrir la revue

Citer ce document

Savard, M. (1981). Extraits de Calendrier. Urgences, (3), 7-16.

https://doi.org/10.7202/025038ar

Ce document est protégé par la loi sur le droit d'auteur. L'utilisation des services d'Érudit (y compris la reproduction) est assujettie à sa politique d'utilisation que vous pouvez consulter en ligne.

https://apropos.erudit.org/fr/usagers/politique-dutilisation/
Cet article est diffusé et préservé par Érudit.

Érudit est un consortium interuniversitaire sans but lucratif composé de l’Université de Montréal, l'Université Laval et l'Université du Québec à Montréal. Il a pour mission la promotion et la valorisation de la recherche. https://www.erudit.org/fr/ 


\section{MICHEL SAVARD}

Extraits de Calendrier 
I'hiver les mouches se reposent les pinsons quelques mauvais sifflements les rassemblent quelques croûtes de pain quelques graines de sésame ouvre-toi petit oiseau terre-de-sienne engoncé dans ton manteau de plumes léger vivant jamais la mort ne te surprend en plein vol je parle de la mort dite naturelle peut-être la nuit te trouve-t-elle sans défense dans ton sommeil jamais on n'entend tes dernières paroles que je sache peut-être n'as-tu rien à dire face à l'irréductible peut-être n'es-tu jamais surpris 
le trottoir roule ses sous neufs ce vendredi le treize oscille son couperet sur les supersticieux la neige cancérigène ne tombe en mars qu'en désespoir de cause aussitôt perdue dans les flaques quelques reflets s'y côtoient ciel blanc corniches briques et fenêtres déformées de l'épicerie bière cidre et vin

ce matin

sans attendre le reflux des migraines les marteaux-pneumatiques tressautent l'éventrement de la ville impassible quelques vieillards à demi-effacés s'égarent parmi leurs brisures de mémoires les coeurs de chocolat sont en solde l'inspecteur des bornes et fontaines énumère ses pieds marins depuis la saint valentin 
cela va de soi chaque année le printemps

honore ses promesses quand le soleil éclate

les bombes des bourgeons le facteur distribue

un grand nombre de lettres d'amour

son sac est allégé son pas plus allègre

le sable sec sous ses semelles

crisse le ciment du trottoir

I'effervescence aussi des molécules de I'air par-dessus les flaques en voie de disparition et tout ce qui grouille sous

le filet des feuilles brunes 
prendre le soleil

quand la fenêtre glisse dans l'axe sans bruit

de sa déflagration chaque jour la montagne passe un peu plus tard sa face cachée de la droite vers la gauche sous une pluie de particules lumineuses 
à la vie à la mort même patience et même frénésie c'est la tombée du jour la rue saint-laurent jonchée d'odeurs tombe ses stores d'acier à la manière des paupières d'une dormeuse sur ses promesses je reviendrai oh je reviendrai demain matin demain même patience et même frénésie n'y a-t-il pas six jours ouvrables à la vie le septième est une fête commémorative de la mort de dieu l'apothéose du sommeil

ce rite de dormir on dit qu'il se perd dans la nuit du temps 
le temps passe comme le papier dernier jour d'automne comment le célébrer le jour le plus court en vibrer bien l'intensité en observer la perfection jusqu'au niveau sub-atomique le jour le plus court il fait froid ce samedi ce premier jour de fin de semaine les calendriers se reposent seuls les enfants intensément les consultent plusieurs fois par jour laissez faire je n'ai rien à révéler sur la fée des étoiles dont n'ait déjà traité penthouse 
observe attentivement observe cette saison comme elle est obscure quand elle faufile ses frissons sous la tissure des tendresses dis-toi la mort ce n'est pas autrement qu'elle investit qu'elle cristallise les cellules rappelle-toi pénètre-toi de ce savoir la lune n'abrite aucune vie même si l'oeil la rêve sous toutes longitudes alors observe bien observe encore ton absence comme elle est belle dans la distance 
deux ou trois nuits de ce noël tout un chacun confusément se propose de tomber de sommeil toi tu n'arriveras pas à fermer l'oeil c'est évident la nuit sort sa griffe blanche cette fille virgule qui dort familière forme femelle et pourtant toi tu ne peux plus la reconnaître tant la terre a tourné l'hiver a bien mal commencé trop tôt ce jour de l'immaculée-conception ferré l'a dit tire-toi 
ce soir de noël sur la rue principale personne ne frissonne toute une population s'est effondrée la fièvre du samedi soir la ranimera peut-être la rue sainte-catherine sera-t-elle à nouveau théâtre d'événements entre les clubs deux cent quatre-vingt-un et trois cent vingt et un les appels de phares nourrissent les rêves des rétroviseurs 